\title{
Processing And Device Performance Of GaN Power Rectifiers
}

\author{
A.P. Zhang ${ }^{(1)}$, G.T. Dang ${ }^{(1)}$, X.A. Cao ${ }^{(2)}$, H. Cho ${ }^{(2)}$, F. $\operatorname{Ren}^{(1)}$, J. Han ${ }^{(3)}$, J.-I. Chyi ${ }^{4)}$, \\ C.-M. Lee ${ }^{(4)}$, T.-E. Nee ${ }^{(4)}$, C.-C. Chuo ${ }^{(4)}$, G.-C. Chi ${ }^{(5)}$, S.N.G. Chu ${ }^{(6)}$, R.G. Wilson ${ }^{(7)}$ \\ and S.J. Pearton ${ }^{-(2)}$ \\ ${ }^{(1)}$ Department of Chemical Engineering \\ University of Florida, Gainesville, FL 32611 USA \\ ${ }^{(2)}$ Department of Materials Science and Engineering \\ University of Florida, Gainesville, FL 32611 USA \\ (3) Sandia National Laboratories, Albuquerque, NM 87185 USA \\ (4) Department of Electrical Engineering \\ National Central University, Chung-Li, 32054 Taiwan \\ ${ }^{(5)}$ Department of Physics, National Central University, Chung-Li 32054 Taiwan \\ (6) Bell Laboratories, Lucent Technologies, Murray Hill, NJ 07974 USA \\ (7) Consultant, Stevenson Ranch, CA 91381
}

\begin{abstract}
Mesa and planar geometry GaN Schottky rectifiers were fabricated on 3-12 $\mu \mathrm{m}$ thick epitaxial layers. In planar diodes utilizing resistive $\mathrm{GaN}$, a reverse breakdown voltage of $3.1 \mathrm{kV}$ was achieved in structures containing p-guard rings and employing extension of the Schottky contact edge over an oxide layer. In devices without edge termination, the reverse breakdown voltage was $2.3 \mathrm{kV}$. Mesa diodes fabricated on conducting GaN had breakdown voltages in the range 200-400 V, with on-state resistances as low as $6 \mathrm{~m} \Omega \cdot \mathrm{cm}^{-2}$.
\end{abstract}

\section{INTRODUCTION}

The AlGaN materials system is attractive from the viewpoint of fabricating unipolar power devices because of its large bandgap and relatively high electron mobility. [1-6] An example is the use of Schottky diodes as high-voltage rectifiers in power switching applications. [2-4,6] These diodes will have lower blocking voltages than $\mathrm{p}-\mathrm{i}-\mathrm{n}$ rectifiers, but have advantages in terms of switching speed and lower forward voltage drop. Edge termination techniques such as field rings or field plates, bevels or surface ion implantation are relatively well-developed for $\mathrm{Si}$ and $\mathrm{SiC}$ and maximize the high voltage blocking capability by avoiding sharp field distributions within the device. [7] However in the few GaN Schottky diode rectifiers reported to date [2,3], there has been little effort made on developing edge termination techniques. Proper design of the edge termination is critical both for obtaining a high breakdown voltage and reducing the on-state voltage drop and switching time.

In this paper we report on the effect of various edge termination techniques on the reverse breakdown voltage, $\mathrm{V}_{\mathrm{B}}$, of planar GaN Schottky diodes which deplete in the lateral direction. A maximum $\mathrm{V}_{\mathrm{B}}$ of $3.1 \mathrm{kV}$ at $25^{\circ} \mathrm{C}$ was achieved with optimized edge termination, which is a record for $\mathrm{GaN}$ devices. We also examined the temperature 
dependence of $V_{B}$ in mesa diodes and found a negative temperature coefficient of this parameter in these structures.

\section{EXPERIMENTAL}

The GaN was grown on c-plane $\mathrm{Al}_{2} \mathrm{O}_{3}$ substrates by Metal Organic Chemical Vapor Deposition using trimethylgallium and ammonia as the precursors. For verticallydepleting devices, the structure consisted of a $1 \mu \mathrm{m} \mathrm{n}^{+}\left(3 \times 10^{18} \mathrm{~cm}^{-3}\right.$, Si-doped $)$ contact layer, followed by undoped $\left(\mathrm{n}=2.5 \times 10^{16} \mathrm{~cm}^{-3}\right)$ blocking layers which ranged from 3$11 \mu \mathrm{m}$ thick. These samples were formed into mesa diodes using Inductively Coupled Plasma etching with $\mathrm{Cl}_{2}$ /Ar discharges ( $300 \mathrm{~W}$ source power, $40 \mathrm{~W}$ rf chuck power). The dc self-bias during etching was $-85 \mathrm{~V}$. To remove residual dry etch damage, the samples were annealed under $\mathrm{N}_{2}$ at $800^{\circ} \mathrm{C}$ for 30 secs. Ohmic contacts were formed by lift-off of e-beam evaporated $\mathrm{Ti} / \mathrm{Al}$, annealed at $700^{\circ} \mathrm{C}$ for 30 secs under $\mathrm{N}_{2}$ to minimize the contact resistance. Finally, the rectifying contacts were formed by lift-off of e-beam evaporated $\mathrm{Pt} / \mathrm{Au}$. Contact diameters of $60-1100 \mu \mathrm{m}$ were examined.

For laterally-depleting devices, the structure consisted of $\sim 3 \mu \mathrm{m}$ of resistive $\left(10^{7}\right.$ $\Omega /$ _ ) GaN. To form ohmic contacts, $\mathrm{Si}^{+}$was implanted at $5 \times 10^{14} \mathrm{~cm}^{-2}, 50 \mathrm{keV}$ into the contact region and activated by annealing at $150^{\circ} \mathrm{C}$ for 10 secs under $\mathrm{N}_{2}$. The resulting $\mathrm{n}$ type carrier concentration was $1 \times 10^{19} \mathrm{~cm}^{-3}$. The ohmic and rectifying contact metallization was the same as described above.

Three different edge termination techniques were investigated for the planar diodes[7]: (i) use of a p-guard ring formed by $\mathrm{Mg}^{+}$implantation at the edge of the Schottky barrier metal. In these diodes the rectifying contact diameter was held constant at $124 \mu \mathrm{m}$, while the distance of the edge of this contact from the edge of the ohmic contact was $30 \mu \mathrm{m}$ in all cases.

(ii) use of p-floating field rings of width $5 \mu \mathrm{m}$ to extend the depletion boundary along the surface of the $\mathrm{SiO}_{2}$ dielectric, which reduces the electric field crowding at the edge of this boundary. In these structures a $10 \mu \mathrm{m}$ wide p-guard ring was used, and 1-3 floating field rings employed.

(iii) use of junction barrier controlled Schottky (JBS) rectifiers, i.e. a Schottky rectifier structure with a p-n junction grid integrated into its drift region.

In all of the edge-terminated devices the Schottky barrier metal was extended over an oxide layer at the edge to further minimize field crowding, and the guard and field rings formed by $\mathrm{Mg}^{+}$implantation and $1100^{\circ} \mathrm{C}$ annealing.

\section{RESULTS AND DISCUSSION}

\section{(a) Effects of Edge Terminations}

Figure 1 (top) shows a schematic of the planar diodes fabricated with the p-guard rings, while the bottom of the Figure shows the influence of guard ring width on $V_{B}$ at $25^{\circ} \mathrm{C}$. Without any edge termination, $\mathrm{V}_{\mathrm{B}}$ is $\sim 2300 \mathrm{~V}$ for these diodes. The forward turnon voltage was in the range $15-50 \mathrm{~V}$, with a best on-resistance of $0.8 \Omega \mathrm{cm}^{2}$. The figureof-merit $\left(\mathrm{V}_{\mathrm{B}}\right)^{2} / \mathrm{R}_{\mathrm{ON}}$ was $6.8 \mathrm{MW} \cdot \mathrm{cm}^{-2}$. As the guard-ring width was increased, we observed a monotonic increase in $\mathrm{V}_{\mathrm{B}}$, reaching a value of $\sim 3100 \mathrm{~V}$ for $30 \mu \mathrm{m}$ wide rings. The figure-of-merit was $15.5 \mathrm{MW} \cdot \mathrm{cm}^{-2}$ under these conditions. The reverse leakage 
current of the diodes was still in the nA range at voltages up to $90 \%$ of the breakdown value.
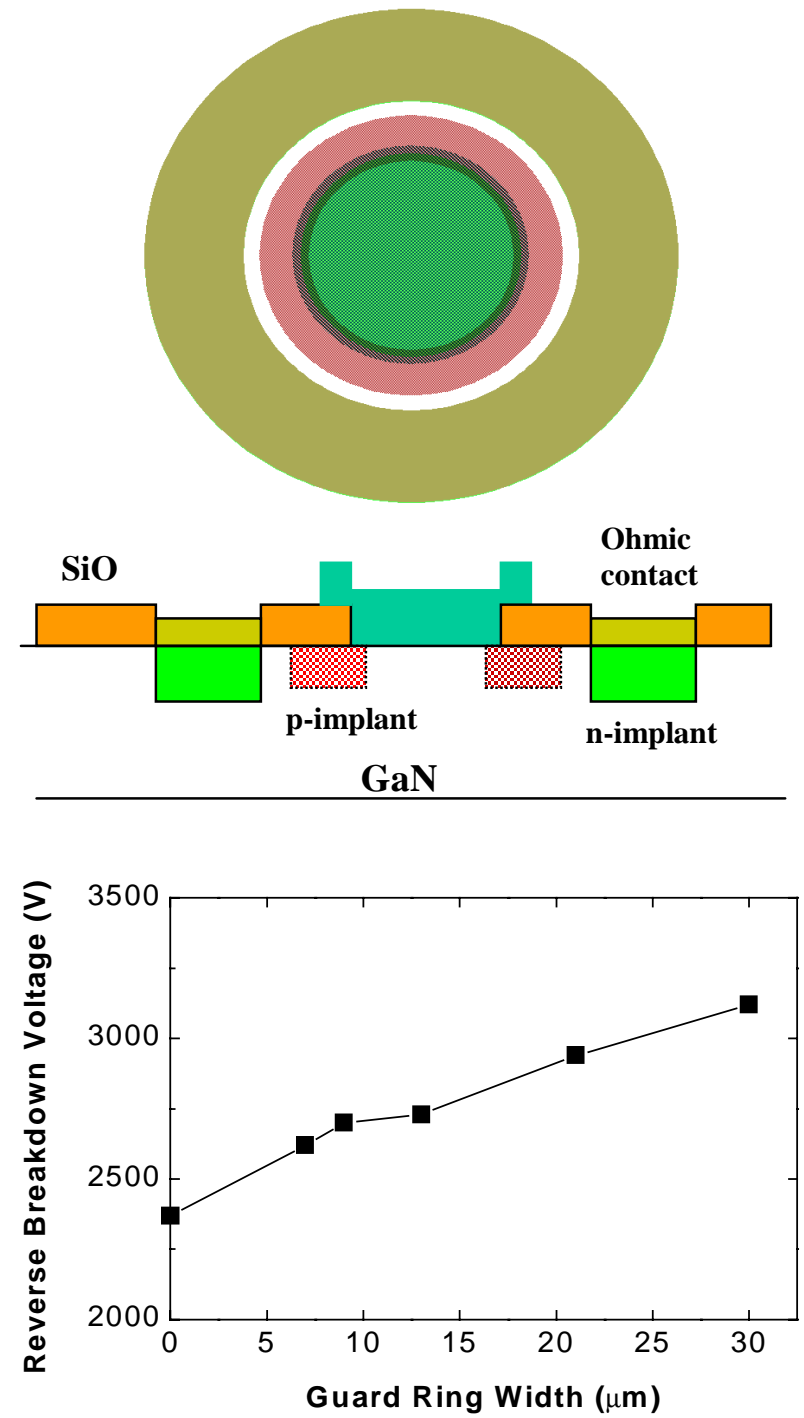

Figure 1. (top) View of rectifiers with p-type guard rings. (bottom) Variation of $V_{B}$ with guard ring width. 
Figure 2 (top) shows a schematic of the floating field ring structures, while the bottom section shows the effect of different edge termination combinations on the resulting $\mathrm{V}_{\mathrm{B}}$ at $25^{\circ} \mathrm{C}$. Note that the addition of the floating field rings to a guard ring structure further improves $\mathrm{V}_{\mathrm{B}}$, with the improvement saturating for a 3 floating field ring geometry.
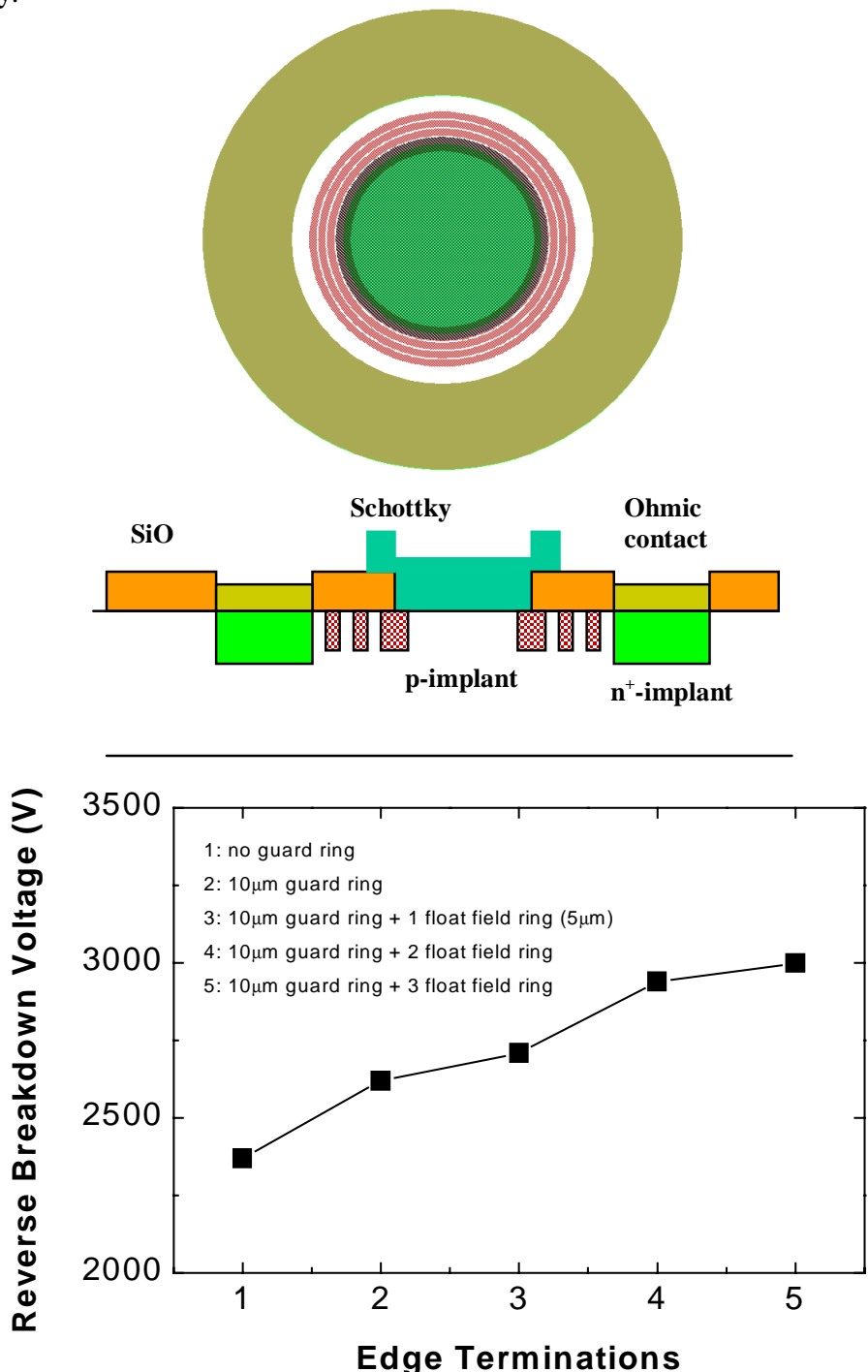

Figure 2. (top) View of rectifiers with floating field rings. (bottom) Variation of $\mathrm{V}_{\mathrm{B}}$ with or without a $10 \mu \mathrm{m}$ wide p-guard rings a 1,2 or 3 floating field rings. The field ring width was $5 \mu \mathrm{m}$ in all cases. 
Figure 3 shows the effect of the junction barrier control on $V_{B}$, together with a schematic of the p-n junction grid. In our particular structure we found that junction barrier control slightly degraded $\mathrm{V}_{\mathrm{B}}$ relative to devices with guard rings and various numbers of floating field rings. We believe that with optimum design of the grid structure we should achieve higher $\mathrm{V}_{\mathrm{B}}$ values and that the current design allows Schottky barrier lowering since the depletion regions around each section of the grid do not completely overlap. This is consistent with the fact that we did not observe the decrease in forward turn-on voltage expected for JBS rectifiers relative to conventional Schottky rectifiers.
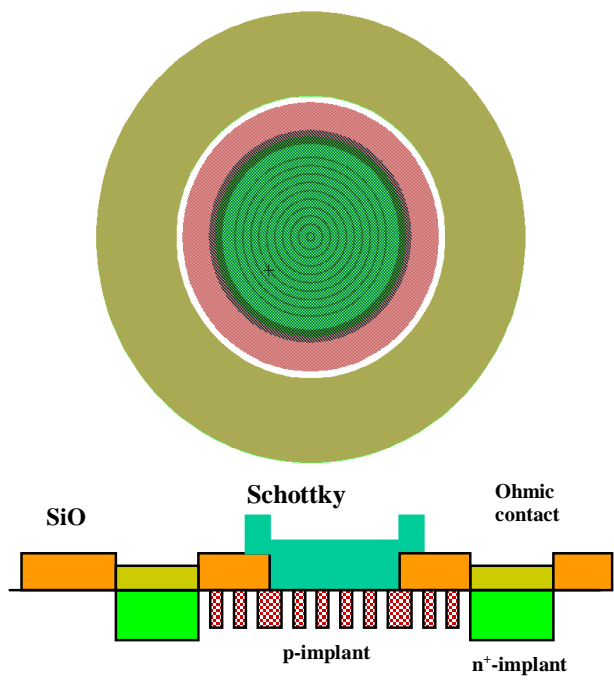

GaN

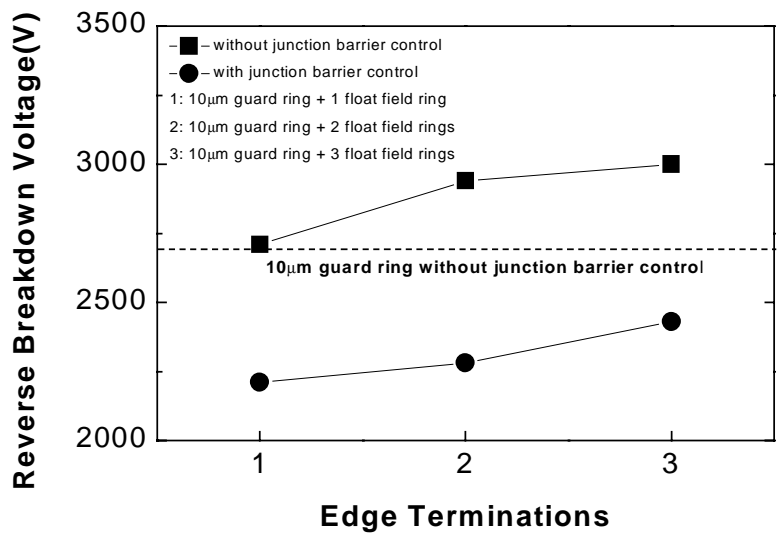

Figure 3. (top) View of rectifier with junction barrier control. (bottom) Variation of $\mathrm{V}_{\mathrm{B}}$ in devices with a $10 \mu \mathrm{m}$ wide p-guard ring and 1, 2 or 3 floating field rings, either with or without junction barrier control. 
The results of Figure 1-3 are convincing evidence that proper design and implementation of edge termination methods can significantly increase reverse breakdown voltage in $\mathrm{GaN}$ diode rectifiers and will play an important role in applications at the very highest power levels. For example, the target goals for devices, intended to be used for transmission and distribution of electric power or in single-pulse switching in the subsystem of hybrid-electric contact vehicles are $25 \mathrm{kV}$ standoff voltage, $2 \mathrm{kA}$ conducting current and a forward voltage drop $<2 \%$ of the standoff voltage. At these power levels, it is expected that edge termination techniques will be essential for reproducible operation.

\section{SUMMARY AND CONCLUSIONS}

GaN Schottky diodes with vertical and lateral geometries were fabricated. A reverse breakdown voltage of $3.1 \mathrm{kV}$ was achieved on a lateral device incorporating $\mathrm{p}$ type guard rings. Several types of edge termination were examined, with floating field rings and guard rings found to increase $\mathrm{V}_{\mathrm{B}}$. The best on-state resistance obtained in these lateral devices was $0.8 \Omega \mathrm{cm}^{2}$. In mesa diodes incorporating $\mathrm{n}^{+}$contact layers, the best onstate resistance was $6 \mathrm{~m} \Omega \mathrm{cm}^{2}$, while $V_{B}$ values were in the range 200-550V. These GaN rectifiers show promise for high power electronics applications.

\section{ACKNOWLEDGMENTS}

The work at UF is partially supported by an NSF grant (DMR-9732865, L. Hess) and by a DARPA/EPRI grant (D. Radack/J. Melcher), no. MDA 972-98-1-0006 monitored by ONR (J. C. Zolper). The work at NCU is sponsored by the National Science Council of R.O.C. under contract no. NSC-88-2215-E-008-012. The work of RGW is partially supported by a grant for ARO (J.M. Zavada). Sandia is a multiprogram laboratory operated by Sandia Corporation, a Lockheed-Martin company, for the US Department of Energy under grant DEAC04-94AL85000.

\section{REFERENCES}

1. M.S. Shur, "GaN-Based Transistors for High Power Applications," Solid-State Electronics $\underline{42}, 2119$ (1998).

2. J.-I. Chyi, C.-M. Lee, C.-C. Chuo, G.C. Chi, G.T. Dang, A.P. Zhang, F. Ren, X.A. Cao, S.J. Pearton, S.N.G. Chu and R.G. Wilson, "Growth and Device Performance of GaN Schottky Rectifiers,” MRS Internet J. Nitride Semicond. Res. 4, 8 (1999).

3. Z.Z. Bandic, D.M. Bridger, E.C. Piquette, T.C. McGill, R.P. Vaudo, V.M. Phanse and J.M. Redwing, "High Voltage (450 V) GaN Schottky Rectifiers," Appl. Phys. Lett. 74, 1266 (1999).

4. M. Trivedi and K. Shenai, "Performance Evaluation of High Power, Wide Bandgap Semiconductor Rectifiers,” J. Appl. Phys. 도, 6880 (1999).

5. V.A. Dmitriev, K.G. Irvine, C.H. Carter, Jr., N.I. Kuznetsov and E.V. Kalinina, "Electric Breakdown in GaN p-n Junctions," Appl. Phys. Lett. 68, 229 (1996).

6. S.J. Pearton, J.C. Zolper, R.J. Shul and F. Ren, "GaN: Processing, Defects and Devices,” J. Appl. Phys. $\underline{86}, 1$ (1999). 